\title{
TENSION PNEUMOCEPHALUS - A RARE BUT TREATABLE CAUSE OF RAPID NEUROLOGICAL DETERIORATION IN TRAUMATIC BRAIN INJURY. A CASE REPORT
}

\section{PNEUMOCEPHALIE SOUS TENSION. UNE CAUSE RARE MAIS TRAITABLE DE DÉTÉRIORATION NEUROLOGIQUE RAPIDE LORS D'UNE LÉSION CÉRÉBRALE TRAUMATIQUE}

KOMOLAFE Edward Oluwole ${ }^{1}$

FANIRAN EA ${ }^{1}$

1. Departments of Surgery and Medicine, Obafemi Awolowo University Teaching Hospitals Complex, Ile-Ife, Osun State, Nigeria

E-Mail Contact - KOMOLAFE Edward Oluwole : eokomolafe (at) hotmail (dot) com

Key words:

Mots clés :T

\section{ABSTRACT}

Pneumocephalus is a frequent complication following head injury and craniotomies. It can become an acute neurosurgical emergency when associated with raised intracranial pressure and neurological deterioration. Early diagnosis and timely appropriate intervention will reduce morbidity and unnecessary mortality from a case as this.

\section{RESUME}

La pneumocéphalie est une complication fréquente au décours d'un traumatisme crânien ou post-crâniotomie. Elle Ce peut représenter une urgence neurochirurgicale en cas d'hypertension intracrânienne avec détérioration neurologique. Un diagnostic précoce ainsi qu'une intervention appropriée réduisent la morbidité et la mortalité.

\section{INTRODUCTION}

Pneumocephalus also called intracranial aerocele or pneumatocele is the presence of air in the subarachnoid pathways, ventricles or the brain substance. It is usually a post-traumatic phenomenon however it can also be iatrogenic. Pneumocephalus is seen in $20-30 \%$ of patients with post-traumatic CSF fistulas. Tension pneumocephalus is usually used to described air trapped under pressure in the intracranial space usually seen when the brain did not expand following removal of chronic subdural clot and also post trauma when there is traumatic pneumocephalus without an overt CSF leakage. Tension pneumocephalus has been reported following silent otitis media, spinal tapping in a patient with basal skull fracture (10), tumors of the base of the skull, and rarely following craniotomy. Other known but rare causes of tension pneumocephalus are scuba diving (12), and otorhinolaryngological procedures (7).

The presence of intracranial air indicates that there is an open communication and should be considered a form of CSF fistula. Air enters the intracranial space after dura tears even without direct brain laceration. The air flows "upstream" along the normal CSF pathways. It is a serious complication and a neurosurgical emergency especially when associated with clinical and neurological deterioration. Pneumocephalus in addition places the patient at an increased risk for meningitis. We report a case of life-threatening tension 
pneumocephalus following traumatic basal skull fracture which required an urgent surgical intervention with dramatic recovery.

\section{CASE REPORT}

$\mathrm{OA}$ is a 23yr old male student, a motorcyclist involved in a road traffic accident during which he sustained head injury associated with basal skull fracture. He had brief loss of consciousness for about five minutes and had transient CSF leak from the left ear. His Glasgow coma score (GCS) on admission was 14. He was admitted for observation but was noticed to be deteriorating neurologically after few hours on admission. His GCS dropped to 9 and the left pupilary size increased to $5 \mathrm{~mm}$ from $3 \mathrm{~mm}$. A cranial CT scan was done which showed multiple air in the intracranial cavilty mostly in the intraventricular space (figures 1a \&1b). These findings are noted with features of intracranial hypertension but no gross midline shift. He had an emergency right frontal ventriculostomy to let out the air and then to drain the CSF. Few minutes after the procedure, he gained consciousness and sustained improvement in his neurological complaints. He continued to make clinical progress and the ventricular drain was removed on the fifth day. He sustained neurological improvement until the parents requested for discharge after eight days on admission. He has seen been lost to follow-up.

\section{DISCUSSION}

Pneumocephalus, which is abnormal presence of air in the cranial cavity, could follow many conditions, commonest being head trauma, then tumors, infections, as well as post surgical procedures of the head. Rarely, it could develop in the scuba diver or spontaneously. In anaesthesia practice it may follow nitrous oxide use especially if it is not discontinued before dura closure, lumbar puncture, spinal/epiddural anaesthesia, positive pressure ventilation (8), and hyperbaric oxygen therapy (6). Other contributing factors for the development of pneumocephalus include head position, duration of surgery, hydrocephalus, intraoperative osmotherapy, hyperventilation, and continuous CSF drainage via lumbar drain (9).

The presence of intracranial air is an indication of an open fracture or a fracture line extending into a sinus. The air collection may be located in the extradural, subdural, subarachnoid, intraventricular, and intracerebral spaces. Intracerebral and intraventricular pneumocephalus occurs when there are tears in the dura and arachnoid layers. Also for the intraventricular pneumocephalus, fulminating, often fatal, intracrannial sepsis may develop.

Basically, two theories have been proposed as the mechanism by which pneumocephalus develop. The first is a ball valve mechanism by Dandy (2), which describes a uni-directional air movement from the outside into the cranial cavity which then gets trapped. The second one is the soda bottle theory proposed by Horowitz (3). This postulated that negative intracranial pressure occur as a result of excessive CSF loss, draining into distensible spinal space, or just draining by a normal physiological mechanism like Valsalva manouvre. In this illustrated case of tension pneumocephalus due to basal skull fracture, both mechanisms could significantly be responsible. The diagnosis of tension pneumocephalus is difficult, as the symptoms and mechanism of injury mimic those associated with intracranial hemorrhage It should however be suspected in neurological deterioration in head injured patients as one of the secondary effects of the trauma. Clinical presentation includes headaches, nausea and vomiting, seizures, dizziness, and depressed neurological status. A significant amount of pneumocephalus can also simulate a space-occupying lesion (9). When pneumocephalus is suspected, CT can play a vital role in determining the precise location of the gas collection, its relationship to the basal skull fracture site or air sinuses, whether the air bubbles were single or multiple (5), and the amount of mass effect on the brain. It is also evident on plain skull $x$-rays and this is important in centres where CT and/or MRI scans are not available. A common feature on the CT scan is the Mount Fuji sign, described by a group of Japanese neurosurgeons in which the two frontal poles are surrounded and separated by air (4). The other usual finding on CT scan is the presence of multiple small air bubbles scattered through several cisterns ("air bubble sign") (4).

Pneumocephalus rarely need surgical intervention except when it is associated with significant neurological deficit and supported with features of tension Pneumocephalus. When indicated, the management involves closing the causative breech in the cerebral integuments but surgical intervention should be done if the CSF leak persists for more than a week. Small volumes of air $<2 c c$ are frequent in head injury and usually resolve without treatment. Large volumes however indicate the possibility of a persistent open communication that requires neuroimaging and possibility of surgical correction. Avoidance of contributing factors, high index of suspicion, and confirmation with neuroimaging are important in attenuating mortality and morbidity. http://ajns.paans.org 
Supplemental oxygen increases the rate of absorption of Pneumocephalus (9). Injuries associated with a pneumatocele or a single intracranial air bubble, have a good prognosis, as do frontobasal lesions. Injuries associated with multiple air bubbles have a bad prognosis (11).

When indicated surgery can be done as open or endoscopic repair (1). This case further illustrates the importance of neuroimaging in making accurate diagnosis to offer adequate treatment. Early diagnosis and timely appropriate intervention will reduce morbidity and unnecessary mortality from a case as this.

\section{FIGURES}

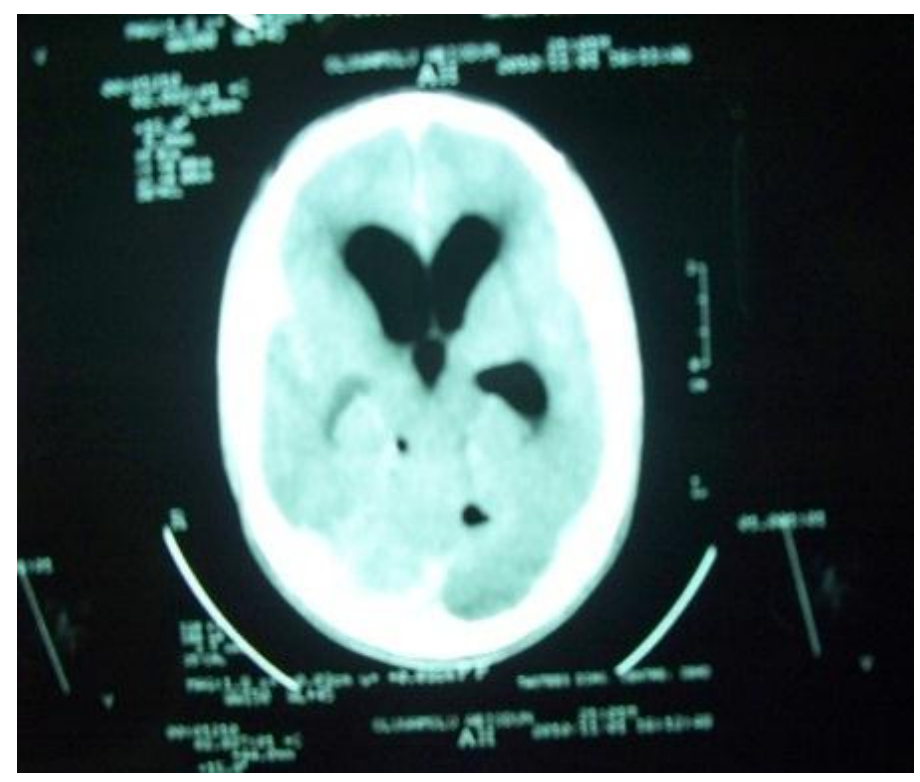

Figure 1a

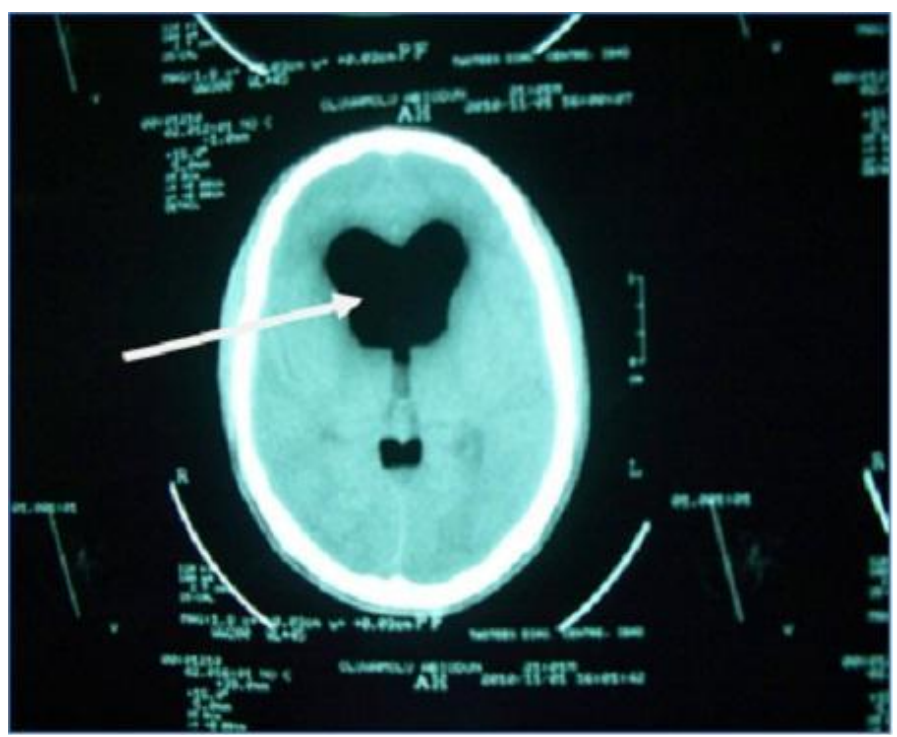

Figure 1b

Figures 1a \&1b: CT brain scan showing air trapped in the ventricles (arrows). 


\section{REFERENCES}

1. CLARK DW, CITARDI MJ, FAKHRI S. Endoscopic management of skull base defects associated with persistent pneumocephalus following previous open repair: a preliminary report. Otolaryngol Head Neck Surg. 2010 Jun;142(6):820-6.

2. DANDY WE. Pneumocephalus (intracranial pneumatocele or aerocele) Arch Surg. 1926;12:949-982.

3. HOROWITZ M. Intracranial pneumocoele. An unusual complication following mastoid surgery. J Laryngol Otol.1964;78:128-134.

4. ISHIWATA Y, FUJITSU K, SEKINO T, FUJINO H, KUBOKURA T, TSUBONE K, KUWABARA T. Subdural tension Pneumocephalus following surgery for chronic subdural haematoma. Journal of Neurosurgery 1988; 68:58-61.

5. KESKIL S, BAYKANER K, CEVIKER N, IalK S, CENGEL M, ORBAY T. Clinical significance of acute traumatic intracranial pneumocephalus. Neurosurg Rev. 1998;21(1):10-3.

6. LEE CH, CHEN WC, WU CI, HSIA TC. Tension pneumocephalus: a rare complication after hyperbaric oxygen therapy. Am J Emerg Med. 2009 Feb;27(2):257.e1-3.

7. MIRZA S, SAEED SR, RAMSDEN RT. Extensive tension pneumocephalus complicating continuous lumbar CSF drainage for the management of CSF rhinorrhoea. ORL J Otorhinolaryngol Relat Spec. 2003;65:215-218.

8. NICHOLSON B, DHINDSA H. Traumatic tension pneumocephalus after blunt head trauma and positive pressure ventilation. Prehosp Emerg Care. 2010 Oct-Dec;14(4):499-504.

9. SCHIRMER CM, HEILMAN CB, BHARDWAJ A. Pneumocephalus: case illustrations and review. Neurocrit Care. 2010 Aug;13(1):152-8.

10. SEUNG HWAN LEE and al. Extensive Tension Pneumocephalus caused by spinal tapping in a patient with basal skull fracture and pneumothorax: a case report. J Korean neurosurg soc. 2009 May; 45(5): 318-321.

11. STEUDEL WI, HACKER $\mathrm{H}$. Prognosis, incidence and management of acute traumatic intracranial pneumocephalus. A retrospective analysis of 49 cases. Acta Neurochir (Wien). 1986;80(3-4):93-9.

12. ZEBA I, BARKOVIC I, KNEZEVIC S, LENDER DM, BRALIC M, BULAT-KARDUM L. Pneumocephalus after an uneventful scuba dive. Aviat Space Environ Med. 2010 May;81(5):511-3. 